\title{
Geociênciajas
}

\section{Rochas ultramáficas plutônicas do greenstone belt Rio das Velhas na porção central do Quadrilátero Ferrífero, Minas Gerais, Brasil}

\author{
Plutonic ultramafic rocks of the greenstone \\ belt Rio das Velhas in the central \\ portion of the Quadrilátero Ferrifero, \\ State of Minas Gerais, Brazil
}

Gabriela Magalhães da Fonseca Mestranda do Programa de Pós-Graduação em Evolução Crustal e Recursos Naturais Departamento de Geologia (DEGEO) Escola de Minas /UFOP gm_fonseca@yahoo.com.br

\section{Hanna Jordt Evangelista}

Professora do Departamento de Geologia (DEGEO) Escola de Minas /UFOP hanna@degeo.ufop.br

\section{Resumo}

Em Amarantina, distrito de Ouro Preto, encontram-se rochas ultramáficas expostas em duas áreas com cerca de $500 \mathrm{~m}^{2}$ cada. As rochas afloram no Complexo do Bação, que é o embasamento gnáissico do greenstone belt Rio das Velhas, na porção central do Quadrilátero Ferrífero (QF). O interesse no estudo petrogenético desses corpos deve-se à preservação parcial de minerais ígneos, ausentes na maior parte das rochas ultramáficas totalmente metamorfizadas do QF. Entre essas rochas, destacam-se os esteatitos e os serpentinitos, devido a sua importância econômica. As rochas ultramáficas de Amarantina possuem textura equigranular, fato que as caracteriza como tendo origem plutônica, isto é, trata-se de metaperidotitos. Possuem grãos maiores de olivina, piroxênio e espinélio da rocha ígnea original distribuídos em matriz metamórfica fina com talco, serpentinas, cloritas, anfibólios e minerais opacos. Escassas arita (NiSbAs) e breithauptita (NiSb) foram formadas a partir de pentlandita durante o metamorfismo associado a hidrotermalismo. A comparação da composição química com a de um metakomatiito com textura spinifex do QF, bem como com rochas komatitiiticas de outras partes do mundo, mostra que os metaperidotitos são, quimicamente, semelhantes aos komatiitos não-desfalcados em alumínio. Portanto é provável que as rochas ultramáficas estudadas correspondam à porção plutônica do magmatismo komatitiitico do Grupo Nova Lima, que é a unidade basal do greenstone belt Rio das Velhas.

Palavras-chave: Rocha ultramáfica, greenstone belt Rio das Velhas, peridotito komatiitico, geoquímica, Quadrilátero Ferrífero, Minas Gerais.

\section{Abstract \\ In Amarantina, district of Ouro Preto (State of Minas Gerais, Brazil), ultramafic rock exposures are found along two areas of about $500 \mathrm{~m}^{2}$ each. The rocks crop out in the Bação complex, which is the gneissic basement of the Rio das Velhas greenstone belt in the central portion of the Quadrilatero Ferrifero $(Q F)$. The interest in a petrogenetic study of the ultramafic rocks is the partial preservation of igneous}


minerals, which are not observed in most of the completely metamorphosed ultramafic rocks in the QF. Among them, the steatites and the serpentinites are the best studied because of their economic importance. The ultramafic rocks from Amarantina are classified as metaperidotites due to the equigranular texture characteristic of plutonic origin. The rocks are made up of large grains of olivine, pyroxene, and spinel preserved from de original magmatic rock, which are distributed in a fine grained mass with talc, serpentine, chlorite, amphibole, and opaque minerals. Scarce arite (NiSbAs) and breithauptite (NiSb) were generated after pentlandite during hydrothermal metamorphism. Comparison of the chemical composition with a metakomatiite with spinifex texture from de QF as well as with known komatiitic rocks from other parts of the world reveals that the metaperidotites are chemically similar to non Al-depleted komatiites. Therefore it is probable that the studied ultramafic rocks correspond to the plutonic portion of the komatiitic magmatism of the Nova Lima group, at the base of the Rio das Velhas greenstone belt.

Keywords: Ultramafic rock, Rio das Velhas greenstone belt, komatiitic peridotite, geochemistry, Quadrilátero Ferrifero, Minas Gerais.

\section{Introdução}

O Quadrilátero Ferrífero $(\mathrm{QF})$ tem sido, desde o século XIX, objeto de pesquisas e estudos geológicos devido aos bens minerais nele presentes, entre os quais se destacam as mineralizações de ferro e ouro. Quanto a bens minerais não-metálicos, são explotadas, entre outras, rochas metaultramáficas do tipo esteatito/serpentinito, de grande importância econômica. Entre as ocorrências de rochas de natureza ultramáfica, encontram-se, muito raramente, corpos que preservam algum mineral ou textura ígnea da rocha original, que são de grande relevância para estudos petrogenéticos, pois podem representar o protólito dos esteatitos e serpentinitos. Nas circunvizinhanças do $\mathrm{QF}$, rochas com minerais ígneos preservados foram descritas por Jordt-Evangelista e Silva (2005), na região de Lamim, ao sul, Fonseca e Pereira (2008), em Lagoa Dourada, a sudoeste, Braga (2006), em Queluzito, também a sudoeste, e Medeiros Júnior e JordtEvangelista (2010), em Acaiaca, a leste do QF. O presente estudo visa à caracte-

\section{Materiais e métodos}

Realizaram-se trabalhos de campo para coleta de amostras, que foram descritas macro e microscopicamente. As lâminas delgadas foram descritas sob microscópio de polarização por luz incidente e luz transmitida. Para se obterem as análises de química mineral, utilizouse o microscópio eletrônico de varredura (MEV) de marca JEOL, modelo JSM com EDS (espectrometria por dispersão de energia) Thermo Electron acoplado no rização de dois corpos ultramáficos com minerais ígneos parcialmente preservados, localizados em Amarantina, distrito de Ouro Preto.

As rochas metaultramáficas da região do Quadrilátero Ferrífero pertencem ao Supergrupo Rio das Velhas, que constitui um greenstone belt arqueano (Dorr, 1969; Ladeira, 1980; Ladeira \& Roeser, 1983; Roeser et al., 1980). O Supergrupo Rio das Velhas é constituído pelo Grupo Nova Lima, inferior, e pelo Grupo Maquiné, superior.

O Grupo Nova Lima é composto, na sua porção basal, principalmente, por esteatitos e serpentinitos derivados de protólitos ígneos ultramáficos (Ladeira \& Roeser, 1983), por meio de processos metamórficos associados a transformações metassomáticas. A preservação de texturas spinifex, embora muito rara (Ladeira, 1980; Noce et al., 1990; Pinheiro \& Nilson, 1997; Andreatta e Silva, 2008), atesta que, pelo menos, uma parte das rochas ultramáficas primárias era de natureza vulcânica, originada de komatiitos.

O Complexo do Bação, no qual estão inseridas as rochas metaultramáficas de Amarantina, é constituído, predominantemente, por gnaisses de composição tonalítica e granodiorítica (Gomes, 1986 e 1987). O referido complexo compõe o embasamento das rochas supracrustais do greenstone belt Rio das Velhas, que o rodeiam. Subordinadamente ocorrem xistos de derivação pelítica e anfibolitos.

O objetivo desse trabalho é o de caracterizar, mineralogicamente e de forma textural e geoquímica, os litotipos presentes nos corpos metaultramáficos de Amarantina e, também, o de empreender sua interpretação petrogenética. A importância do estudo desses corpos se deve a sua localização geográfica, pois estão inseridos dentro do Complexo do Bação, na região central do $\mathrm{QF}$, o que os distingue das ocorrências anteriormente citadas, que se localizam fora do QF e que, portanto, podem não pertencer ao Grupo Nova Lima.
Laboratório de Microanálise (MICROLAB) do DEGEO-UFOP, que operou sob condições analíticas de $20 \mathrm{kV}$, com largura de feixe $10 \mu \mathrm{m}$ e 2000 contagens. Também foram realizadas análises por microssonda eletrônica em equipamento da marca JEOL, modelo JCXA-8900RL no Laboratório de Microanálises do consórcio Física-Química-Geologia da UFMG e CDTN-CNEN. O aparelho operou com uma tensão de 15 kVe cor- rente de feixe de $20 \mathrm{nA}$. Análises químicas em rocha total foram obtidas via Espectrômetro de Fluorescência de Raios X (FRX), de marca Philips PW2404, modelo MagiX com amostrador automático PW2504 e tubo de Rh a 2,4 kW, no Laboratório de Preparação de Amostras para Geoquímica e Geocronologia (LOPAG) do DEGEO-UFOP e em Espectrofotômetro de Emissão Atômica com Fonte Plasma (ICP-OES), de marca Spectro 
e modelo Ciros CCD, no Laboratório de Geoquímica Ambiental (LGqA) do
DEGEO-UFOP. O tratamento dos dados geoquímicos foi feito no software Minpet versão 2.02 (Richard, 1995).

rantina (Figura 1) é de, pelo menos, 500 $\mathrm{m}^{2}$, conforme indica a distribuição dos afloramentos in situ e dos blocos dispersos pelo terreno. O outro corpo tem dimensões semelhantes.
Figura 1

Mapa geológico do Quadrilátero Ferrífero (modificado de Alkmim \& Marshak, 1998) e mapa de localização dos afloramentos das rochas metaultramáficas.

Figura 2 Imagens de rochas metaultramáficas da região de Amarantina. A) Afloramento do metaperidotito (AM-4).

B) Bloco do espinélio metaperidotido (AM-3). C) Amostra de mão do metaperidotito (AM-1). D) Amostra de mão do metaperidotito (AM-4) dobrado. metros (Figura 2). São rochas maciças, de granulometria fina a média, e que podem apresentar dobras (Figura 2 D). Não se encontraram afloramentos que permitissem verificar as relações de contato com os gnaisses do Complexo do Bação. A área superficial do corpo a leste de Ama-
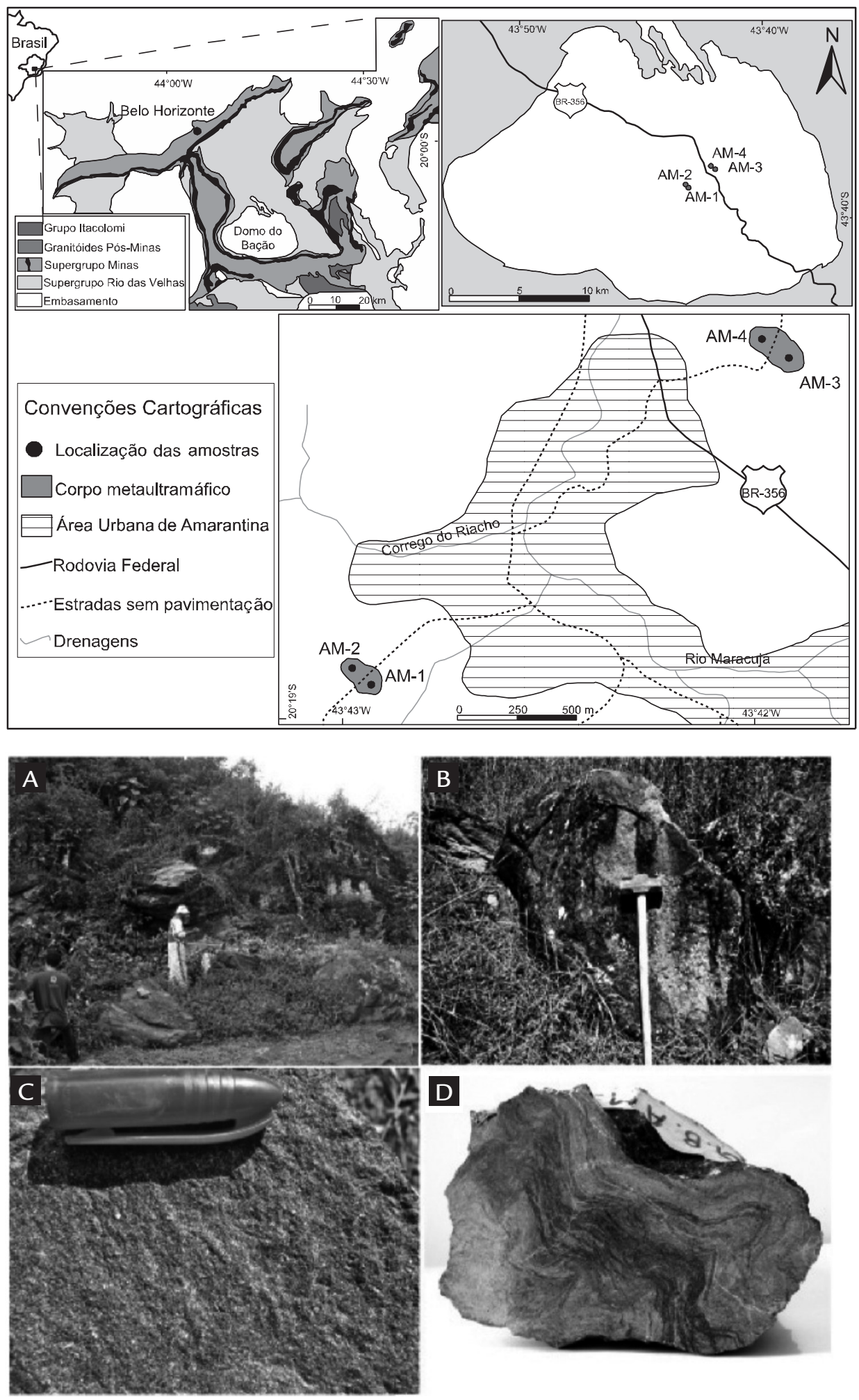


\section{Aspectos petrográficos e química mineral}

No corpo metaultramáfico de Amarantina, foram amostrados três litotipos, a saber, espinélio metaperidotito, metaperidotito e tremolita-clorita-serpentina granofels, sendo que este último representa o produto do total metamorfismo dos anteriores. As amostras estudadas foram coletadas nos pontos AM-1 a AM-4, mostrados na Figura 1. Além dos litotipos citados, são encontrados, também, esteatitos, que, devido ao elevado grau de alteração intempérica, não foram amostrados.

O metaperidotito AM-1 (Figura 3 F) possui até $20 \%$ de olivina, que ocorre em grãos maiores distribuídos em matriz fina composta por clinoanfibólio, serpentina, clorita, talco, magnetita e ilmenita. Os grãos de olivina, que ficaram preservados da rocha ígnea, são arredondados, medem cerca de $0,8 \mathrm{~mm}$ e possuem alteração nas fraturas e bordas em serpentina e talco. A fórmula estrutural média da olivina, obtida por meio de análises de microssonda, é $\mathrm{Mg}_{1,6} \mathrm{Fe}_{0,4} \mathrm{Si}_{0,99} \mathrm{O}_{4}$, com $80 \%$ do componente forsterita. O clinoanfibólio apresenta-se em cristais prismáticos e incolores, que foi identificado por MSE e MEV/EDS como magnésiohornblenda. Pela inexistência de feições texturais do tipo spinifex e tendo em vista o hábito da olivina, interpreta-se que a textura original da rocha é plutônica e não vulcânica.

O tremolita-clorita-serpentina granofels AM-2 encontra-se com cerca de $200 \mathrm{~m}$ do metaperidotito AM-1. Embora não apresente minerais ígneos preserva- dos, é provável, pela proximidade, que seja produto do metamorfismo do metaperidotito. Tem microestrutura decussada e é constituído por tremolita (15\%), serpentina $(55 \%)$, clorita $(20 \%)$, talco (5\%) e Cr-magnetita (5\%).

O espinélio metaperidotito AM-3 (Figura 3 A, B, C, D) possui minerais de origem ígnea, como olivina, ortopiroxênio e espinélio, que somam até $30 \%$ do volume da rocha, e proporções variáveis de tremolita, serpentina, clorita, talco, ilmenita, Cr-magnetita, breithauptita e arita, que, juntos, constituem os restantes $70 \%$ da rocha. A olivina aparece em cristais anédricos de até $0,8 \mathrm{~mm}$, com alteração para talco e serpentina. A fórmula estrutural média da olivina, obtida por meio de análises de MSE (Tabela 1), é $\mathrm{Mg}_{1,7} \mathrm{Fe}_{0,3} \mathrm{Si}_{0,99} \mathrm{O}_{4}$, que corresponde a $85 \%$ do componente forsterita. $\mathrm{O}$ ortopiroxênio, com fórmula estrutural $\mathrm{Ca}_{0,33}\left(\mathrm{Mg}_{1,71} \mathrm{Fe}_{0,29}\right) \mathrm{Si}_{1,97} \mathrm{O}_{6}$, isto é, com En 85, encontra-se substituído, parcialmente, por talco, serpentina e tremolita, gerados por reações metamórficas em condições da fácies xisto verde. O espinélio ocorre em grãos anédricos, medindo cerca de $0,2 \mathrm{~mm}$, tem cor verde-escura e encontra-se sempre rodeado por clorita. A sua fórmula estrutural média é $\left(\mathrm{Mg}_{0,65} \mathrm{Fe}_{0,35}\right) \mathrm{Cr}_{0,1} \mathrm{Al}_{1,9} \mathrm{O}_{4}$, o que corresponde a uma composição intermediária entre espinélio s.s. e hercinita, sendo, por isso, classificado como pleonasto.

O metaperidotito AM-4 (Figura 3 E) apresenta-se com cerca de $30 \%$ de olivina, que ocorre em grãos maiores distribuídos em matriz fina composta por tremolita, serpentina, clorita, talco e minerais opacos, classificados por MSE e MEV/EDS como ilmenita, magnetita, Cr-magnetita, pirita, pentlandita, breithauptita e arita. Olivina apresenta-se, parcialmente, alterada. Em geral, os grãos estão envoltos por massa fibrosa formada por serpentina, menos frequentemente observa-se clorita e talco. Os grãos chegam até a $1,5 \mathrm{~cm}$. A porcentagem de componente Fo é $87 \%$ e sua fórmula estrutural é $\mathrm{Mg}_{1,7} \mathrm{Fe}_{0,3} \mathrm{Si}_{0,99} \mathrm{O}_{4}$.

Localmente verifica-se que a rocha apresenta-se bandada e dobrada (Figura 4). O bandamento mineralógico é dado pela alternância de bandas, onde a olivina está preservada com bandas ricas em minerais metamórficos, como serpentinas, cloritas, talco ou tremolita. Essas bandas, provavelmente, representam descontinuidades, por onde houve a infiltração dos fluidos aquosos durante o metamorfismo. A ausência de extinção ondulante, nos grãos de olivina, sugere que o peridotito original não estava dobrado, mas que o processo tectonometamórfico levou à geração de dobras por deslizamento ao longo das descontinuidades, onde se formaram os minerais mais dúcteis, como serpentinas, clorita ou talco.

Minerais contendo antimônio e arsênio, como breithauptita e arita (Figura $5)$, não são comuns. A arita (NiSbAs) representa o membro de composição intermediária da solução sólida niquelina (NiAs) - breithauptita (NiSb), estudada,

\begin{tabular}{c|c|c|c|c|c}
\hline Rochas & $\begin{array}{c}\text { Metaperidotito } \\
\text { (AM-1) }\end{array}$ & \multicolumn{3}{|c|}{$\begin{array}{c}\text { Espinélio Metaperidotito } \\
\text { (AM-3) }\end{array}$} & $\begin{array}{c}\text { Metaperidotito } \\
\text { (AM-4) }\end{array}$ \\
\hline Minerais & Olivina & Olivina & Ortopiroxênio & Espinélio & Olivina \\
\hline $\mathrm{SiO}_{2}$ & 38,91 & 39,90 & 56,97 & 0,02 & 39,24 \\
\hline $\mathrm{TiO}_{2}$ & 0,01 & 0,01 & 0,04 & 0,02 & 0,00 \\
\hline $\mathrm{Al}_{2} \mathrm{O}_{3}$ & 0,08 & 0,01 & 0,49 & 62,24 & 0,01 \\
\hline $\mathrm{Cr}_{2} \mathrm{O}_{3}$ & 0,01 & 0,01 & 0,07 & 3,81 & 0,02 \\
\hline $\mathrm{FeO}$ & 20,03 & 14,03 & 9,80 & 16,68 & 13,32 \\
\hline $\mathrm{MnO}$ & 0,18 & 0,19 & 0,15 & 0,12 & 0,16 \\
\hline $\mathrm{MgO}$ & 41,07 & 45,93 & 32,99 & 16,61 & 47,15 \\
\hline $\mathrm{ZnO}$ & - & - & - & 0,25 & - \\
\hline $\mathrm{CaO}$ & 0,02 & 0,01 & 0,08 & 0,01 & 0,00 \\
\hline $\mathrm{NiO}$ & 0,28 & 0,20 & 0,00 & 0,25 & 0,30 \\
\hline $\mathrm{NaO}$ & - & - & 0,02 & 0,01 & - \\
\hline $\mathrm{K}{ }_{2} \mathrm{O}$ & - & - & 0,03 & 0,01 & - \\
\hline $\mathrm{Total}$ & 100,59 & 100,29 & 100,62 & 100,03 & 100,20 \\
\hline
\end{tabular}

Tabela 1

Composição química média (\% peso) de minerais do metaperidotito AM-1, espinélio metaperidotito AM-3 e metaperidotito AM-4. 
experimentalmente, por Hewitt (1948). A composição química média de porcentagem em peso encontrada para a pentlandita foi de $36 \%$ de $\mathrm{Fe}, 28 \%$ de Ni e $37 \%$ de S, para a breithauptita foi de $34 \%$ de $\mathrm{Ni}$ e $66 \%$ de $\mathrm{Sb}$ e para a arita de $\mathrm{Ni}(42-37 \%)$, de As (39-32\%) e de Sb (25$16 \%)$. Breithauptita, arita e pentlandita aparecem com intercrescimento (Figura 5). O intercrescimento da breithauptita com arita e pentlandita reflete processos substitucionais, provavelmente decorrentes de variações na concentração de elementos como As, S e Sb, onde a pen- tlandita cede ao Ni. Breithauptita pode ser encontrada em depósitos minerais formados em altas pressões e temperaturas, como em peridotitos, em pegmatitos niquelíferos com pirrotita e disseminada em veios de galena-esfalerita. Entretanto sua ocorrência é mais comum em veios hidrotermais com Co-Ni-Ag (Ramdhor, 1969).

Embora minerais de $\mathrm{Ni}-\mathrm{As}-\mathrm{Sb}$ sejam relativamente raros na natureza, eles não são incomuns em variadas mineralizações relacionadas a remobilizados hidrotermais, onde ocorrem associados com minerais de ouro (Cook, 1996). No entanto, a presença de $\mathrm{Au}$, Co e Ag não foi verificada nas rochas estudadas nesse trabalho.

Para fins de comparação com as rochas de Amarantina, coletou-se e analisou-se uma amostra de metakomatiito de Rio Manso, na região noroeste do QF (Andreatta e Silva, 2008). A amostra SPF possui textura spinifex preservada e é composta por $35 \%$ em volume de talco, $25 \%$ de clorita, 20\% de clinoanfibólio, $15 \%$ de serpentina, $5 \%$ de carbonatos e $5 \%$ de minerais opacos.
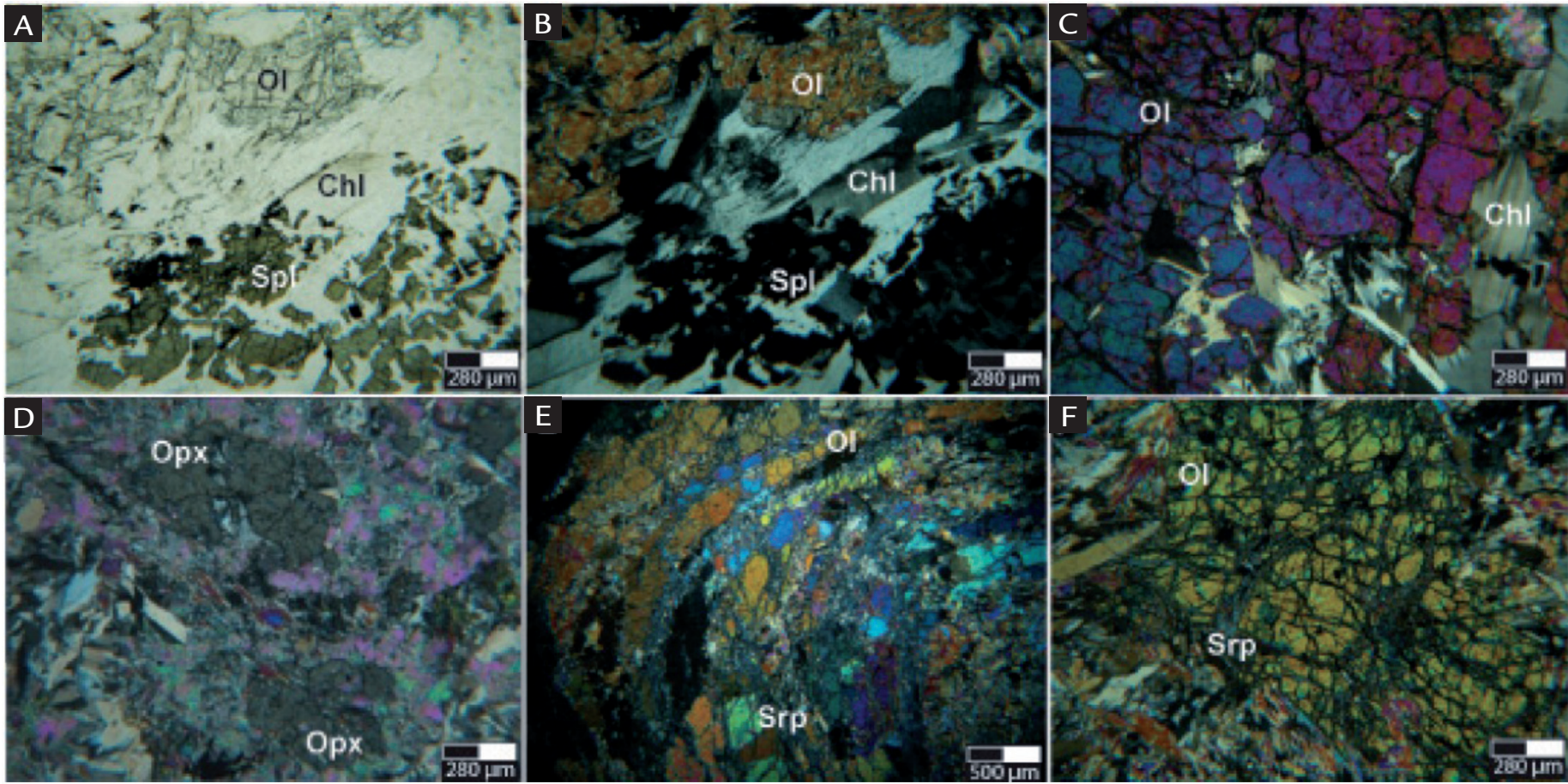

Figura 3

Fotomicrografias das rochas metaultramáficas de Amarantina. A) Espinélio metaperidotito (AM-3) com olivina (OI) e espinélio (Spl) preservados e clorita (Chl) metamórfica. LPP (polarizadores planos); B) Idem. LPX (polarizadores cruzados). C) Espinélio metaperidotito (AM-3) com olivina (Ol) e clorita (Chl). LPX (polarizadores cruzados). D) Espinélio metaperidotito (AM-3) com ortopiroxênio (Opx) preservado. LPX(polarizadores cruzados). E) Metaperidotito (AM-4) com grão de Olivina (OI) parcialmente serpentinizados (Srp) orientados segundo dobras. LPX (polarizadores cruzados). F) Metaperidotito (AM-1) com grão de Olivina (Ol) parcialmente serpentinizados (Srp). LPX (polarizadores cruzados).

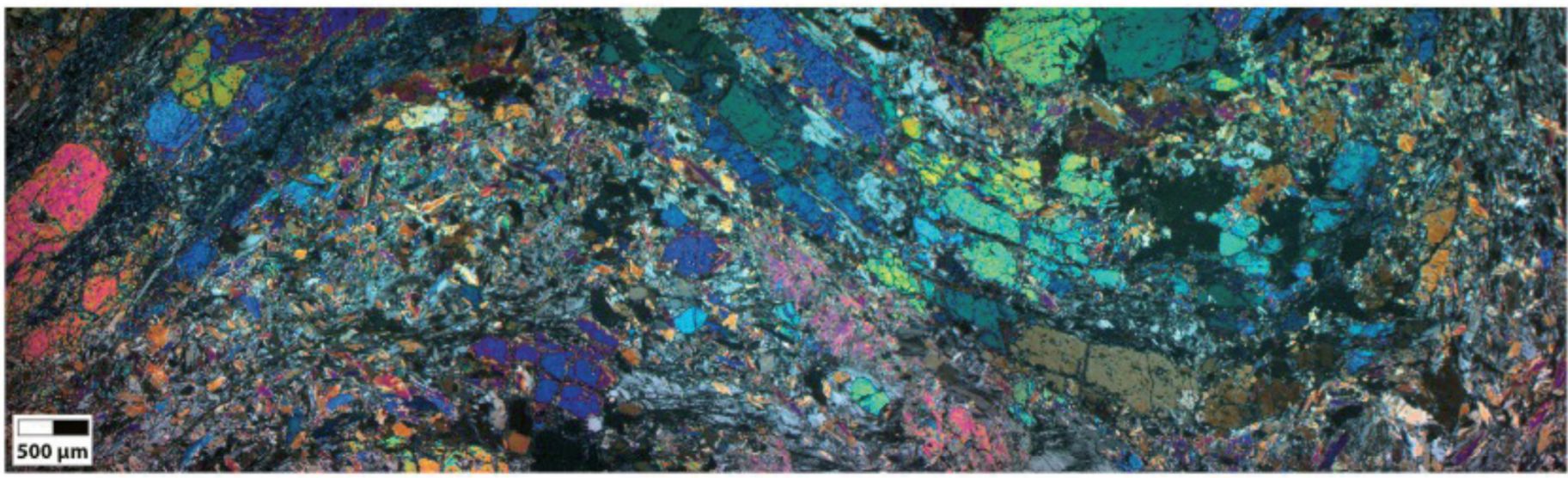

Figura 4

Mosaico de fotomicrografias do metaperidotito dobrado em polarizadores cruzados (AM-4), realizado com o software Canon PhotoStitch 1.6.0. 

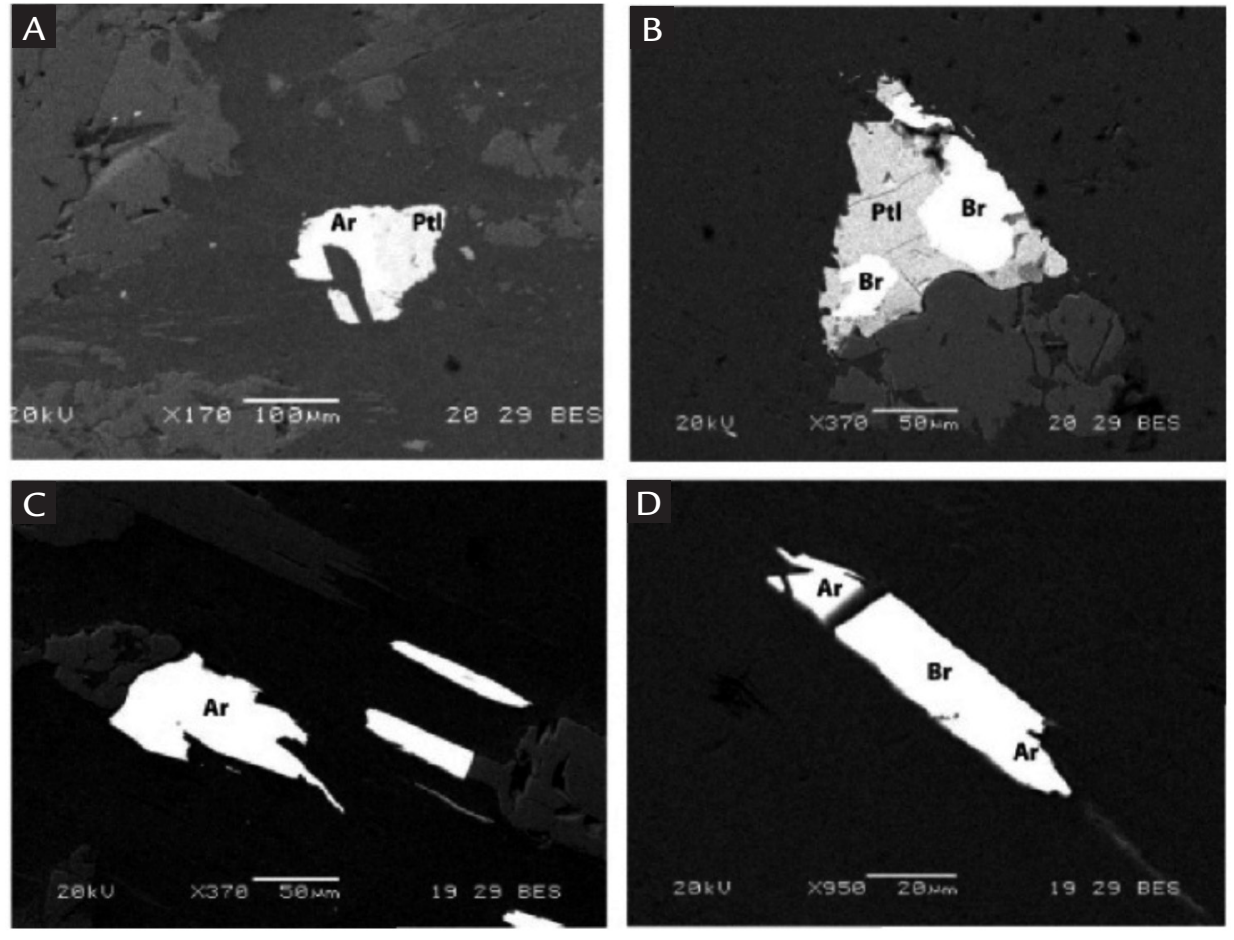

\section{Geoquímica}

A Tabela 2 apresenta os resultados das análises químicas das amostras estudadas e rochas similares selecionadas da literatura para comparação. As rochas da literatura são o komatiito peridotítico de Yakabindie, na Austrália (Naldrett \& Turner, 1977 in Naldrett \& Cabri, 1976) e o komatiito de Abitibi, no Canadá (Sun \& Nesbitt, 1978 in Arndt, 2008). Embora totalmente metamorfizada, a amostra de metakomatiito SPF, da região de Rio Manso no QF, foi incluída por ainda preservar a textura spinifex e, portanto, por ser uma rocha representativa dos derrames ultramáficos do Grupo Nova Lima.

Verifica-se que as rochas de Amarantina, tal como o metakomatiito de Rio Manso e as rochas da literatura, possuem altos teores de $\mathrm{MgO}$, de 25 a $33 \%$ em peso e Cr e Ni muito elevados (Cr: 1771 a 3555 ppm; Ni: 843 a 1572 ppm). Os teores anômalos de As e Sb, em média, 470 e 500 ppm, respectivamente, são devidos à presença dos minerais breithauptita (NiSb) e arita (NiSbAs).

Segundo Arndt e Nisbet (1982), peridotitos komatiiticos caracterizam-se, quimicamente, por teores de $\mathrm{MgO}$ acima de $18 \%$ em peso e $\mathrm{TiO}_{2}$ abaixo de $0,9 \%$. Dentro desses critérios, todas as rochas analisadas são peridotitos komatiiticos
(Tabela 2), pois o teor de $\mathrm{MgO}$ varia entre cerca de 25 e $33 \%$ em peso e o $\mathrm{TiO}_{2}$ é inferior a $0,3 \%$.

Segundo Viljoen e Viljoen (1982) e Arndt e Nisbet (1982), outro aspecto importante na definição da suíte komatiitica diz respeito à razão $\mathrm{CaO} / \mathrm{Al}_{2} \mathrm{O}_{3}$ que deve estar situada no intervalo entre 0,8 e 1,0. Nos litotipos estudados, as razões de $\mathrm{CaO} / \mathrm{Al}_{2} \mathrm{O}_{3}$ estão entre 0,6 e 2,73 (Tabela 2). Os litotipos que apresentam razões relativamente elevadas são rochas com grande quantidade de tremolita (AM-1, AM-3). No caso dos litotipos com baixas razões de $\mathrm{CaO} / \mathrm{Al}_{2} \mathrm{O}_{3}(0,6)$, trata-se de amostras com altos teores de clorita. Portanto a razão $\mathrm{CaO} / \mathrm{Al}_{2} \mathrm{O}_{3}$ não é primaria nas rochas estudadas, possivelmente devido à mobilidade do cálcio durante o processo de metamorfismo acompanhado de infiltração de fluidos aquosos, que propiciaram a geração de minerais hidratados como talco e serpentinas à custa de minerais anidros como olivina e piroxênios.

Nesbitt et al. (1979) e Beswick (1982, in Arndt \& Nisbet, 1982) propõem uma classificação para os komatiitos em dois grupos baseados na razão $\mathrm{Al}_{2} \mathrm{O}_{3} / \mathrm{TiO}_{2}$. O primeiro grupo apresenta valores aproximadamente condríticos com razão $\mathrm{Al}_{2} \mathrm{O}_{3} / \mathrm{TiO}_{2}$ em torno de
Figura 5

Imagens de elétrons retroespalhados obtidas por MEV.

A) Pentlandita ( $\mathrm{Ptl})$ intercrescida com arita (Ar).

B) Pentlandita ( $\mathrm{Ptl}$ ) intercrescida com breithauptita $(\mathrm{Br})$.

C) Arita (Ar).

D) Breithauptita $(\mathrm{Br})$ no centro e arita (Ar) nas bordas.
20,4, o que caracteriza a suíte de komatiitos não-desfalcados em $\mathrm{Al}$. O segundo grupo, classificado como dos komatiitos $\mathrm{Al}$-desfalcados, é caracterizado por apresentar razões próximas da metade dos valores condríticos, o que o ocorre nos komatiitos do oeste da Austrália (Beswick 1982). A maioria das amostras estudadas apresenta razão $\mathrm{Al}_{2} \mathrm{O}_{3} / \mathrm{TiO}_{2}$ próximas ou maiores do que 20,4 correspondendo à suíte de komatiitos nãodesfalcados em Al.

Para caracterizar, quimicamente, as rochas de Amarantina, as análises foram lançadas em diagramas discriminantes (Figura $6 \mathrm{~A}$ ); para fins de comparação também foram utilizadas as análises da literatura e o metakomatiito de Rio Manso. No diagrama de Jensen (1976), verifica-se que as amostras possuem características químicas de peridotitos komatiiticos, com exceção do tremolita-clorita-serpentina granofels (AM-2), que se situou no campo de Basalto Komatiitico, provavelmente por ter sido mais afetado pelo processo metamórfico/metassomático.

No diagrama $\mathrm{MgO}-\mathrm{CaO}-\mathrm{Al}_{2} \mathrm{O}_{3}$ (Figura 6 B) de Viljoen e Viljoen (1969), também se verifica que as rochas estudadas possuem características geoquímicas de peridotitos komatiiticos.

\section{Discussão e conclusões}

Por se localizarem no Complexo do Bação, que é o embasamento das ro- chas supracrustais da porção central do Quadrilátero Ferrífero, os dois corpos estudados de Amarantina constituem uma ocorrência ímpar para o estudo das 


\begin{tabular}{|c|c|c|c|c|c|c|c|}
\hline Óxidos & $\begin{array}{c}\text { Metaperidotito } \\
\text { AM-1 }\end{array}$ & \begin{tabular}{|} 
Tremolita-clorita- \\
serpentina \\
granofels \\
AM-2
\end{tabular} & $\begin{array}{c}\text { Espinélio } \\
\text { metaperidotito } \\
\text { AM-3 }\end{array}$ & $\begin{array}{c}\text { Metaperidotito } \\
\text { AM-4 }\end{array}$ & $\begin{array}{c}\text { Komatiito } \\
\text { de Rio } \\
\text { Manso } \\
\text { SPF }\end{array}$ & $\begin{array}{c}\text { Komatiito } \\
\text { Peridotítico } \\
\text { de Yakabindie, } \\
\text { Austrália } \\
\text { Kom-2 }\end{array}$ & $\begin{array}{l}\text { Komatiito } \\
\text { de Abitibi, } \\
\text { Canadá Abi }\end{array}$ \\
\hline $\mathrm{SiO}_{2}$ & 45,19 & 40,5 & 47,55 & 45,73 & 45,02 & 44,0 & 45,9 \\
\hline $\mathrm{TiO}_{2}$ & 0,23 & 0,30 & 0,14 & 0,13 & 0,23 & 0,27 & 0,35 \\
\hline $\mathrm{Al}_{2} \mathrm{O}_{3}$ & 3,97 & 6,15 & 4,74 & 4,3 & 5,86 & 5,27 & 6,49 \\
\hline $\mathrm{FeO}_{\mathrm{t}}^{*}$ & 8,11 & 12,74 & 7,14 & 8,13 & 8,64 & 10,95 & 10,8 \\
\hline $\mathrm{MnO}$ & 0,18 & 0,14 & 0,13 & 0,14 & 0,14 & 0,22 & 0,19 \\
\hline $\mathrm{MgO}$ & 26,78 & 25,38 & 28,46 & 33,13 & 26,27 & 32,5 & 29,2 \\
\hline $\mathrm{CaO}$ & 10,84 & 3,68 & 6,72 & 3,29 & 5,77 & 5,48 & 6,25 \\
\hline $\mathrm{Na}_{2} \mathrm{O}$ & 0,24 & 0,41 & 0,4 & 0,07 & 0,29 & 0,01 & 0,22 \\
\hline $\mathrm{K}_{2} \mathrm{O}$ & 0,1 & 0,05 & 0,06 & 0,03 & 0,06 & 0,01 & 0,08 \\
\hline $\mathrm{P}_{2} \mathrm{O}_{5}$ & 0,02 & 0,04 & 0,02 & 0,02 & 0,02 & 0,0 & 0,03 \\
\hline $\mathrm{Cr}_{2} \mathrm{O}_{3}$ & 0,26 & 0,51 & 0,27 & 0,33 & 0,49 & - & 0,38 \\
\hline $\mathrm{NiO}$ & 0,17 & 0,11 & 0,15 & 0,20 & 0,13 & - & 0,18 \\
\hline $\mathrm{PPC}^{* *}$ & 3,26 & 7,93 & 3,59 & 4,2 & 6,5 & - & - \\
\hline Total & 99,35 & 97,94 & 99,37 & 99,70 & 99,42 & 98,71 & 100,07 \\
\hline As & - & - & 581 & 358 & - & - & - \\
\hline $\mathrm{Ba}$ & 14,3 & 6 & 6,3 & 7 & 8,2 & - & - \\
\hline Co & 83,6 & 108,8 & 63 & 83,7 & 76,5 & - & - \\
\hline $\mathrm{Cr}$ & 1771 & 3514 & 1871 & 2229 & 3355 & - & - \\
\hline $\mathrm{Cu}$ & 75,8 & 71,3 & 7,2 & 2,3 & 5 & - & - \\
\hline $\mathrm{Ni}$ & 1354 & 843 & 1183 & 1572 & 1058 & - & - \\
\hline $\mathrm{Pb}$ & 16,8 & 79 & 12,1 & 10,2 & 10,5 & - & - \\
\hline $\mathrm{Sb}$ & - & - & 584 & 414,3 & - & - & - \\
\hline $\mathrm{Sr}$ & 64,3 & 4,4 & 20,2 & 16,3 & 14,2 & - & - \\
\hline $\mathrm{V}$ & 89,7 & 111,6 & 80,1 & 80,3 & 131,6 & - & - \\
\hline $\mathbf{Y}$ & 43,1 & 49,1 & 4,8 & 3,4 & 5,7 & - & - \\
\hline $\mathrm{Zn}$ & 64,1 & 162,1 & 37,5 & 58,2 & 65,6 & - & - \\
\hline $\mathrm{Zr}$ & 5,6 & 3,9 & 2,4 & - & 8,3 & - & - \\
\hline $\begin{array}{l}\mathrm{CaO} / \\
\mathrm{Al}_{2} \mathrm{O}_{3}\end{array}$ & 2,73 & 0,60 & 1,42 & 0,77 & 0,67 & 1,04 & 0,96 \\
\hline $\begin{array}{c}\mathrm{Al}_{2} \mathrm{O}_{3} / \\
\mathrm{TiO}_{2}\end{array}$ & 17,26 & 20,50 & 33,86 & 33,08 & 25,48 & 19,52 & 18,54 \\
\hline
\end{tabular}

Composição química (óxidos em \% peso, elementos-traços em ppm) dos litotipos de Amarantina e da literatura geológica.

"Todo o Fe total recalculado como $\mathrm{Fe}_{2} \mathrm{O}_{3}$. ${ }^{* *} \mathrm{PPC}$ - perda por calcinação.

rochas ultramáficas da região. A textura equigranular das amostras, que ainda preservam minerais ígneos, como olivina, indica que as rochas são de origem plutônica, isto é, que não se trata de derrames de komatiito que se caracterizam pela textura spinifex, conforme encontrados localmente no QF. Os resultados de análises químicas mostram que as rochas estudadas são, quimicamente, semelhantes a komatiitos não-desfalcados em Al. Portanto as rochas ultramáficas de Amarantina, provavelmente, correspondem à porção plutônica do magmatismo que deu origem ao Grupo Nova Lima, que é a unidade basal do greenstone belt Rio das Velhas. Ao atravessar a crosta primitiva gnáissica, parte do magma gerador das rochas ultramáficas vulcânicas komatiiticas pode ter preenchido condutos, fraturas ou formado corpos de pequeno porte, conforme os encontrados em Amarantina, cristalizando-se como rocha plutônica. A transformação metamórfica foi somente parcial em talco, serpentinas, anfibólios e/ou carbonatos, o que contrasta com a esteatitização ou serpentinização completa da maior parte das rochas ultramáficas encontradas no QF. A referida transformação deve ser decorrente do aporte insuficiente de fluidos aquosos durante o ciclo tectonometamórfico do Transamazônico. 


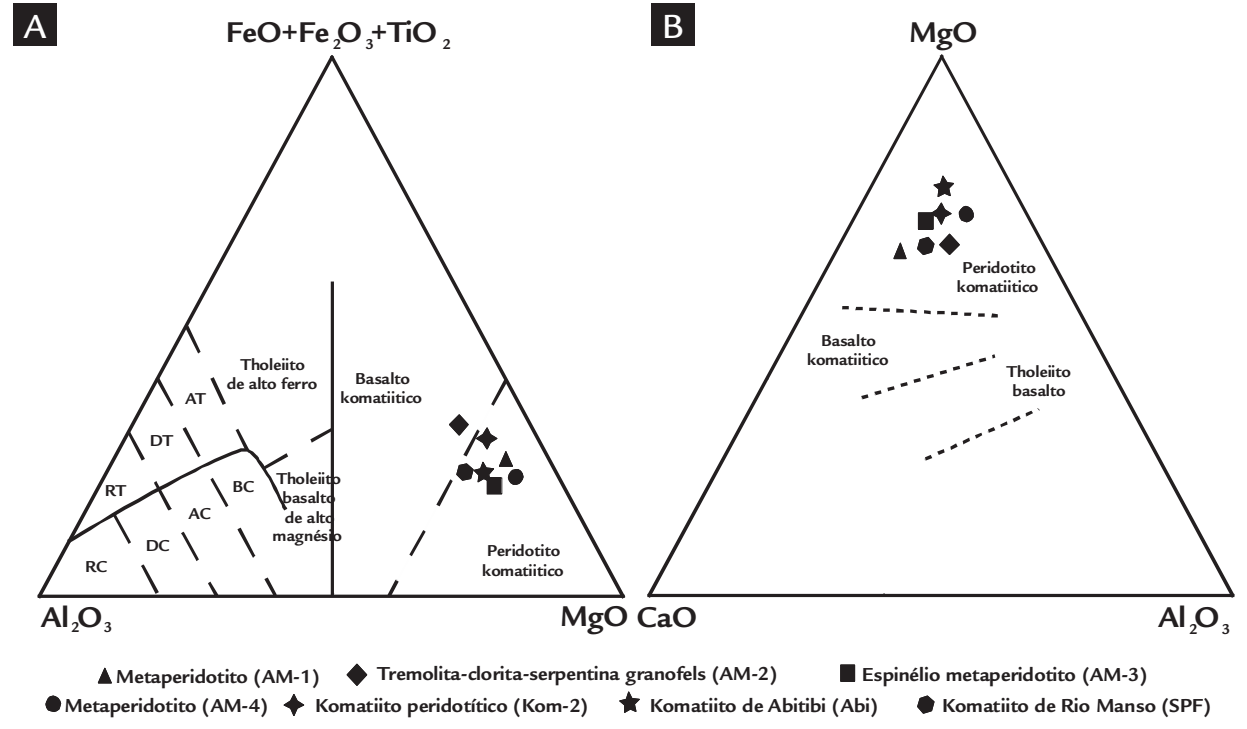

\section{Agradecimentos}

As autoras agradecem à CAPES (Coordenação de Aperfeiçoamento de Pessoal de Nível Superior) pela bolsa de

mestrado da primeira autora. E, também, à Universidade Federal de Ouro Preto pelas análises de MEV/EDS, ICP-
Figura 6

Diagramas geoquímicos.

A) Diagrama discriminante de Jensen (1976) modificado por Rickwood (1989) in Rollinson (1993), para komatiitos, tholeiitos e rochas cálcio-alcalinas, onde AT- Andesito tholeiitico; DT-Dacito tholeiitico; RT-Riolito tholeiitico; BCBasalto calcioalcalino; AC- Andesito calcioalcalino; DC- Dacito calcioalcalino; RC- Dacito calcioalcalino.

B) Diagrama triangular ( $\mathrm{MgO}-\mathrm{CaO}-$ $\mathrm{Al}_{2} \mathrm{O}_{3}$ ), segundo Viljoen e Viljoen (1969).

OES e Fluorescência de Raios X e à Universidade Federal de Minas Gerais pelas análises de MSE.

\section{Referências Bibliográficas}

ALKMIM, F. F., MARSHAK, S. Transamazonian Orogeny in the Southern São Francisco Craton Region, Minas Gerais, Brazil: Evidence for the Paleoproterozoic collision and collapse in the Quadrilátero Ferrífero. Precambrian Research, v. 90, p. 29-58, 1998.

ANDREATTA e SILVA, G. P. A Sequência Vulcano-Sedimentar Arqueana Rio Manso-Complexo Metamórfico Campo Belo Setentrional, Minas Gerais. Ouro Preto: Departamento de Geologia, Escola de Minas, Universidade Federal de Ouro Preto, 2008. 93p. (Dissertação de Mestrado).

ARNDT, N. T., NISBET, E. G. Komatiites. London, George Allen and Unwin, 1982. 526p. ARNDT, N. T. Komatiite: Cambridge University Press. 2008. 467p.

BESWICK, A. E. Some geochemical aspects of alteration, and genetic relations. In: komatiitic suites. In: ARNDT, N. T., NISBET, E. G. (ed.). Komatiites, London: George Allen and Unwin, 1982. cap. 7, p. 283-308526p.

BRAGA, S. A. Geologia da Folha SF-23-X-A-VI-2 (Conselheiro Lafaiete, Minas Gerais)/ Ortofotocarta 42-17-22, Universidade Federal de Ouro Preto, 2006. 62p. (Trabalho de Graduação, n. 417).

COOK, N. J. Mineralogy of the ore deposits at Sulitjelma, Northern Norway. Ore Geology Review. v. 11, p. 303-338, 1996.

DORR, J. V. N. II Physiographic, stratigraphic and structural development of the Quadrilátero Ferrífero, Minas Gerais, Brazil. U.S. Geological Survey Professional Paper, 641-A. U.S. Geological Survey. p. 1-110, 1969.

FONSECA, G. M., PEREIRA A. B. Contribuição à Geologia da Folha Resende Costa (SF-23-X-A-V-4) (Lagoa Dourada, Minas Gerais): ortofotocarta 42-22-20. Universidade Federal de Ouro Preto, 2008. 88p. (Trabalho de Graduação, n. 456).

GOMES, N. S. Caracterização química de paragêneses minerais de alto grau metamórfico no Complexo do Bação, Quadrilátero Ferrífero, Minas Gerais. REMRevista Escola de Minas, v. 40, n. 1, p. 25-36, 1987.

GOMES, N. S. Determinações geotermométricas e geobarométricas em paragêneses minerais de alto grau metamórfico no Complexo do Bação, Quadrilátero Ferrífero - Minas Gerais. In: CONGRESSO BRASILEIRO DE GEOLOGIA 34, Anais... Goiânia, Goiás. p. 1424-1436, 1986.

HEWITT, D. F. A partial study of the NiAs-NiSb system. Economic Geology, v. 43, p. 408-417, 1948.

JENSEN, L. S. A new method of classifying subalcalic volcanic rocks. Ontario Division of Mines, Miscellaneous Paper. v. 66, p. 1-22, 1976. 
JORDT-EVANGELISTA, H., SILVA, M. E. Rochas metaultramáficas de Lamim, sul do Quadrilátero Ferrífero, MG: contribuição ao conhecimento do protólito da pedra-sabão. REM - Revista Escola de Minas, Ouro Preto. v. 58, n. 1, p. 11-20. 2005.

LADEIRA, E. A. Metallogenesis of Gold at the Morro Velho Mine, and in Nova lima District, Quadrilátero Ferrifero, Minas Gerais, Brazil. London: University of Western Ontário, 1980. 272p. (Ph.D Thesis).

LADEIRA, E. A., ROESER, H. M. P. Petrography of the Rio das Velhas Greenstone Belt, Quadrilátero Ferrífero, Minas Gerais, Brazil. Stuttgart: Zentralblatt Geologie Palaeontologie, v.3/4, p. 430-450, 1983.

NOCE, C. M., PINHEIRO, S. O., LADEIRA, E. A., GROSSI SAD, J.H. Ocorrência de metakomatiitos com textura spinifex no Grupo Nova Lima, oeste do Quadrilátero Ferrífero, MG. In: CONGRESSO BRASILEIRO DE GEOLOGIA, 36, Boletim de Resumos... Natal, SBG, p. 215. 1990.

MEDEIROS JÚNIOR, E. B., JORDT-EVANGELISTA, H. Petrografia e geoquímica dos granulitos do Complexo Acaiaca, região Centro-Sudeste de Minas Gerais. REM - Revista Escola de Minas, Ouro Preto. v. 62, n. 2, p. 1-10, 2010.

NALDRETT, A. J., CABRI, L. J. Ultramafic and related mafic rocks: their classification and genesis with special reference to the concentration of nickel sulfides and platinum-group elements. Economic Geology, v. 71, p. 1131-1158, 1976.

NESBITT, R. W. SUN, S. S., PURVIS, A. C. Komatiites: geochemistry and genesis. Canadian Mineralogist, v.17 p. 165-186, 1979.

PINHEIRO, S. de O., NILSON, A. A. Parada 10: Morro da Onça - Município de Rio Manso. In: SIMPÓSIO SUL-AMERICANO DE GEOLOGIA ISOTÓPICA. Campos do Jordão, Guia das Excursões... Campos do Jordão, SBG, p. 93-94, 1997.

RAMDOHR, P. The ore minerals and their intergrowths. Pergamon Press, 1969. $1174 p$.

RICHARD, L. R. Minpet for Windows - Version 2.02. Minpet Geological Software, Québec. 1995.

ROESER, U., ROESER, H., MULLER, G. \& TOBSCHALL, H. J. Petrogênese dos esteatitos do sudeste do Quadrilátero Ferrífero. In: CONGRESSO BRASILEIRO GEOLOGIA. 31, Santa Catarina, 1978. Anais... SBG. v. 4, p. 2340-2345, 1980.

ROLLINSON, H.Using GeochemicalData:Evaluation, Presentation, Interpretation. Longman New York: Scientific \& Technical, 1993. 312 p.

VILJOEN, M. J., VILJOEN, R. P. The geology and geochemistry of the lower ultramafic unit of the Onverwacht Group and a proposed new class of igneous rock. Geological Society of South Africa v.2 p. 221-244, 1969.

VILJOEN, R. P., VILJOEN M. J. Komatiites - an historical review. In: ARNDT, N. T., NISBET, E. G. (ed.). Komatiites, London: George Allen and Unwin, 1982. cap.1, p. 5-17. 526p.

Artigo recebido em 22 de agosto de 2011. Aprovado em 28 de fevereiro de 2013. 